\title{
EFICIÊNCIA DO HERBICIDA PYRITHIOBAC APLICADO EM PÓS-EMERGÊNCIA NO CONTROLE DE PLANTAS DANINHAS NA CULTURA DO ALGODÃO ${ }^{1}$
}

\author{
JOSÉ C. V. ALMEIDA² e CÉLIO R. F. LEITE ${ }^{3}$
}

\section{RESUMO}

O presente trabalho teve por objetivo verificar a eficiência do herbicida pyrithiobac aplicado em pós-emergência na cultura do algodoeiro, para o controle das espécies Cenchrus echinatus (capim-carrapicho) e Ipomoea grandifolia (corda-de-viola) em dois estádios de crescimento e de maneira seqüencial, com doses fracionadas. O pyrithiobac na dose de $0,5 \mathrm{l} / \mathrm{ha}$ adicionado do surfactante IHARAGUEN-S a $0,25 \% \mathrm{v} / \mathrm{v}$, em pós-emergência, numa única aplicação ou duas aplicações em doses fracionadas e seqüenciais $(0,25 \mathrm{l} / \mathrm{ha}+0,25 \mathrm{l} / \mathrm{ha})$ foi eficiente no controle das espécies $C$. echinatus e I. grandifolia nos estádios de 1 a 3 e 3 a 4 folhas, respectivamente.

A fitointoxicação ao cultivar reagente IAC-20 foi inicialmente observado, mas os sintomas desapareceram a partir dos 15 dias, não havendo prejuízos à cultura.

Palavras chave: Gossypium hirsutum, Cenchrus echinatus, Ipomoea grandifolia, pyrithiobac, pós-emergência.

\section{ABSTRACT \\ Efficiency of the herbicide pyrithiobac applied in post-emergence to control weeds in cotton}

The present paper had the objective to verify the efficiency of the herbicide pyrithiobac applied in post-emergence for cotton in order to control the species Cenchrus echinatus and Ipomoea grandifolia, in two different growth stage and in sequential way in fraction rates. The product pyrithiobac, in the rate of $0,51 /$ ha plus Iharagen-S at $0,25 \% \mathrm{v} / \mathrm{v}$, in post-emergence in one single rate, or two spraying in fraction rates
$(0,25 \mathrm{l} / \mathrm{ha}+0,25 \mathrm{l} / \mathrm{ha})$ was efficient to control both species, C. echinatus and I. grandifolia in the stage of 1 to 3 and 3 to 4 leaves, respectively. The fitotoxicity to the reagent cultivar IAC-20 was initially observed, but the symptom disappeared in the fifth day, without hazard injury to the crop.

Key words: Gossypium hirsutum, Cenchrus echinatus, Ipomoea grandifolia, pyrithiobac, post-emergence.

\section{INTRODUÇÃO}

A cultura do algodão amplamente disseminada no Brasil, tem como finalidade básica, a obtenção de fibras têxteis de boa qualidade, cujo material é o mais importante dentre as fibras naturais, e assim, a cultura assume posição de destaque como uma das mais cultivadas em diversas regiões brasileiras.
Dentre os fatores que podem afetar o algodoeiro, está a competição exercida pelas plantas daninhas bem como sua interferência física no momento da colheita que reduz a eficiência da operação e também piora a qualidade da fibra, dependendo das espécies presentes na lavoura. Segundo Blanco \& Oliveira (1976), a produção

\footnotetext{
${ }^{1}$ Recebido para publicação em 12/02/98 e na forma revisada em 08/10/98.

2 Prof. Adjunto, Universidade Estadual de Londrina. CEP 86051 -970, Londrina/PR.

${ }^{3}$ Eng $^{\circ}$. Agr ${ }^{\circ}$, SPRAY DROP. CEP 86072-280, Londrina/PR.
} 
pode ser diminuída em até $95 \%$ se as ervas não forem controladas adequadamente.

Normalmente um único processo para o controle de plantas daninhas não é suficiente para dar condições de colheita no limpo. Isto se deve ao ciclo da cultura relativamente longo, às vezes, de até 150 dias, e fitotecnicamente empregado espaçamento entre linhas relativamente grande, o que se constitui num fator negativo no fechamento da cultura num curto espaço de tempo, possibilitando reinfestações tardias, mesmo quando são utilizados herbicidas residuais no plantio (Cruz,1979).

Desse modo, a utilização de herbicidas de pós-emergência um pouco antes do "fechamento" do dossel da cultura (cerca de 0,40 a $0,60 \mathrm{~m}$ de altura) se faz necessário, visando principalmente as plantas que podem causar problemas na colheita. Segundo Almeida \& Rodrigues (1988), os produtos mais indicados para esta finalidade são o diuron e o MSMA, ou a mistura destes, tendo o cuidado de atingir somente as plantas daninhas que é possível somente em aplicações com jato-dirigido, evitando-se o contato do produto com as folhas do algodoeiro, o que causaria fitotoxicação, sem no entanto, reduzir-lhe a produção. Isso se faz necessário em razão de não existir ainda no mercado herbicidas latifoliadicidas de pós-emergência que sejam seletivos ao algodoeiro (Azevedo et al., 1984; Cruz \& Borgo, 1980; Marcondes \& Chehata, 1988).

Portanto, um herbicida com essas características, ou seja, de pós-emergência em área total e seletivo a cultura, seria uma alternativa interessante no combate às plantas daninhas do algodoeiro.

O objetivo do presente experimento, foi verificar a eficiência e praticabilidade agronômica do herbicida pyrithiobac, aplicado em pós-emergência, no controle de plantas daninhas em estádios inicial e normal na cultura do algodão, bem como verificar a fitotoxicação no algodoeiro cultivado no sistema convencional em solo argiloso.

\section{MATERIAL E MÉTODOS}

$\mathrm{O}$ presente experimento foi conduzido no período agrícola de 1994/95, na Fazenda Experimental da Universidade Estadual de Londrina, PR, na latitude de $23^{\circ} 18^{\prime} \mathrm{S}$ e longitude de $51^{\circ} 10^{\prime} \mathrm{W}$, com clima identificado como Cfa na escala de Köeppen.

O solo no local do ensaio é identificado como Latossolo roxo distrófico, textura argilosa, contendo $53 \%$ de argila e $2,04 \%$ de matéria orgânica na profundidade de 0,0 a $0,2 \mathrm{~m}$.

$\mathrm{O}$ delineamento experimental foi o de blocos ao acaso com 8 tratamentos e 4 repetições, constituindo as unidades experimentais por parcelas medindo $2,40 \times 6,0$ metros, ou seja, $14,4 \mathrm{~m}^{2}$ e contendo 4 linhas de algodão.

Os tratamentos com suas respectivas doses e dados da formulação comercial encontram-se na Tabela 1.

A cultivar reagente do algodão foi a IAC20 , semeada no dia 05/11/94 no espaçamento de $0,80 \mathrm{~m}$ entre linhas e numa densidade de 15 sementes por metro. Depois de 25 dias da semeadura foi feito o desbaste manual, deixando 7 plantas/metro.

A primeira aplicação dos tratamentos, em pós-emergência inicial, foi realizada no dia 07/11/94 (32 dias após a semeadura da cultura) no horário das 9:00 às 10:30 horas. $\mathrm{O}$ solo encontrava-se com bastante umidade, decorrente de precipitações de $78 \mathrm{~mm}$ nos 3 dias, que antecederam a aplicação. No momento da aplicação a umidade relativa do ar era de $79 \%$, temperatura ambiente de $26^{\circ} \mathrm{C}$, ausência de vento e céu claro. A segunda aplicação em pósemergência normal, foi realizada no dia 13/12/94 (38 dias após a semeadura), no horário das 19:30 às 20:00 horas. O solo encontrava-se úmido, umidade relativa do ar era de $70 \%$, temperatura do ar de $27^{\circ} \mathrm{C}$, vento calmo e céu claro. A terceira e última aplicação, apenas dois tratamentos, referentes à dose seqüencial dos tratamentos com doses fracionadas, em estádios inicial e normal das plantas daninhas, foi realizada, ambas no dia 30/12/93 (55 dias após a semeadura). O solo encontrava-se úmido, umidade relativa do ar de $69 \%$, temperatura do ar de $24{ }^{\circ} \mathrm{C}$, céu claro e 
TABELA 1. Tratamentos utilizados, doses do ingrediente ativo em $1 /$ ha, tipo de aplicação e dados da formulação comercial dos produtos utilizados no experimento na cultura do algodão. Londrina/PR. 1994/95.

\begin{tabular}{|c|c|c|c|}
\hline TRATAMENTOS & $\begin{array}{l}\text { MODO DE } \\
\text { APLICAÇÃO }\end{array}$ & $\begin{array}{c}\text { DOSE } \\
\text { (kg.i.a./ha) }\end{array}$ & $\begin{array}{l}\text { CONCENTRAÇÃO } \\
(\mathrm{g} / \mathrm{kg} \text { ou } \mathrm{l})\end{array}$ \\
\hline 1-Testemunha capinada & -- & -- & -- \\
\hline 2-Testemunha s/ capina & -- & -- & -- \\
\hline 3-pyrithiobac & PÓS INICIAL & $0,07 \ldots . .0,07$ & 280 \\
\hline 4-pyrithiobac & PÓS NORMAL & $0,07 \ldots . .0,07$ & 280 \\
\hline 5-pyrithiobac & PÓS INICIAL & 0,140 & 280 \\
\hline 6-pyrithiobac & PÓS NORMAL & 0,140 & 280 \\
\hline 7-MSMA & PÓS NORMAL & 1,680 & 480 \\
\hline 8-MSMA + diuron & PÓS NORMAL (JD) & $2,5+1,4$ & $480 / 500$ \\
\hline \multicolumn{4}{|l|}{ Notas: } \\
\hline \multicolumn{4}{|c|}{ 1) Pós inicial : quando as plantas daninhas encontravam-se no estádio de 1 a 3 folhas. } \\
\hline \multicolumn{4}{|c|}{ 2) Pós normal : quando as plantas daninhas encontravam-se no estádio de 3 a 4 folhas. } \\
\hline \multicolumn{4}{|c|}{ 3) ... $\quad$ : significa aplicações seqüenciais como doses parceladas, repetindo-se quando uma nova geração de plantas } \\
\hline \multicolumn{4}{|c|}{$\begin{array}{l}\text { daninhas encontravam-se no mesmo estádio quando da primeira aplicação. } \\
\text { : Jato-dirigido }\end{array}$} \\
\hline
\end{tabular}

ausência de ventos, sendo que o horário da aplicação foi das $8: 30$ horas às $8: 45$ horas. Nesta aplicação seqüencial pretendia-se inicialmente estádios de plantas daninhas de 1 a 3 e 3 a 4 folhas respectivamente, em estádios inicial e normal de crescimento para utilização do herbicida, com as mesmas sendo proveniente de uma nova geração. No entanto, em razão da demora no surgimento e desenvolvimento dessa nova geração, talvez em função de atividade residual da primeira dose do produto no solo,. a aplicação dos dois tratamentos foi realizado com as plantas estando com 1 a 2 folhas. Caso esperasse atingir as 3 ou 4 folhas necessárias para o estádio normal, inviabilizaria a prática, um vez que o dossel das plantas estaria "fechado", tornando deficiente a pulverização do herbicida.

Para aplicação dos tratamentos, utilizou-se um pulverizador costal propelido a $\mathrm{CO}_{2}$, equipado com barra contendo 4 bicos do tipo leque, Teejet 110.03 , que trabalhando a uma altura de $0,35 \mathrm{~m}$ do alvo e numa velocidade de $1,0 \mathrm{~m} / \mathrm{s}$ propiciou um volume de 250 litros de calda por hectare. A faixa aplicada foi de 2,0 metros de largura e a pressão do pulverizador, mantida constante, foi de 2,8 $\mathrm{kg} / \mathrm{cm}^{2}$.

As plantas daninhas que surgiram na área do ensaio, servindo de alvo de avaliações, foram essencialmente, capim-carrapicho (Cenchrus echinatus), numa densidade de 112 plantas $/ \mathrm{m}^{2}$, e corda-de-viola (Ipomoea grandifolia), numa densidade de 16 plantas $/ \mathrm{m}^{2}$. Por ocasião da aplicação do tratamento em pós-emergência inicial (PÓSi) as duas primeiras espécies encontravam-se no estádio de 1 a 3 folhas, e em pós-emergência normal (PÓSn) encontravam-se no estádio de 3 a 4 folhas; na aplicação seqüência destes dois estádios, que seriam os mesmos da primeira aplicação, nos dois casos realizou-se com as plantas daninhas com 1 a 2 folhas.

Para verificar a eficiência dos herbicidas, foram realizadas 4 avaliações visuais aos 07, 15, 44 e 54 dias após aplicação (DAA) dos tratamentos, utilizando-se uma escala de avaliação visual de ensaios de herbicidas, qual seja a aplicação de notas de $0-100 \%$ de eficiência de controle nas plantas daninhas ou injúria à cultura do algodão. 


\section{RESULTADOS E DISCUSSÃO}

Encontram-se na Tabela 2, as médias das porcentagens de controle da espécie $C$. echinatus, conseguidas através de avaliações visuais realizadas aos 7, 15, 44 e 54 dias após a aplicação (DAA) dos primeiros e/ou únicos tratamentos. Sendo que o intervalo de aplicação entre o POSi, plantas daninhas com 1 a 3 folhas, e o POSn, plantas daninhas com 3 a 4 folhas, foi de 6 dias (32 e 38 dias após a semeadura do algodão, respectivamente). Os tratamentos seqüenciais nesses dois estádios preconizados para controle foram realizados no mesmo dia, isto é, aos 55 dias após a semeadura do algodoeiro, quando as plantas daninhas encontravam-se com 1 a 2 folhas, aos 23 e 17 dias após a aplicação da primeira dose desses tratamentos. Esta antecipação dos tratamentos seqüenciais, sobretudo para o estádio normal de controle, no qual a recomposição matoflorística também deveria estar em estádio de 3 a 4 folhas, deveu-se a demora dessa recomposição. Com isto o estádio da cultura passou a ser um fator limitante na utilização do herbicida, que estando mais desenvolvida, certamente interferiria na eficiência da pulverização se realizada posteriormente.

Aos 7 DAA o controle da espécie em questão pelo herbicida pyrithibac mais o surfactante IHARAGUEN-S, na proporção de $0,25 \% \mathrm{v} / \mathrm{v}$, foi eficiente quando a mesma se encontrava em estádio inicial de crescimento, quer na dose de $0,51 /$ ha, numa única aplicação, ou com apenas a metade desta dose, isto é, 0, 25 1/ha, em que os índices de controle foram ao redor de $82 \%$; e com as plantas daninhas em estádio normal de controle ( 3 a 4 folhas), inicialmente apenas a maior dose foi eficiente, com índice de $80,1 \%$, enquanto a menor dose propiciou $77,3 \%$.

No entanto não houve diferenças estatísticas entre esses tratamentos, independentemente da dose ou do estádio das plantas daninhas. Porém, foram inferiores à testemunha capinada e ao tratamento padrão (MSMA + diuron) que estavam com 100\% de controle. O MSMA sozinho, na dose de 3,5 1/ha, foi deficiente, com índice de $71,3 \%$ apenas.
Aos 15 DAA em todos os tratamentos os índices de controle melhoraram, passando a ser eficientes a exceção do MSMA. Nessa época o destaque com herbicida pyrithiobac, foi para os tratamentos realizados em POSi nos quais os índices foram acima de 90\%, enquanto em POSn, os índices situavam-se no patamar de $80 \%$. Havendo semelhanças estatísticas das doses dentro de cada estádio, e entre as doses cheias independente do estádio de crescimento estabelecido para controle.

Aos 44 DAA, quando os tratamentos seqüenciais já haviam recebido a segunda dose, e tendo decorrido 24 DAA, a eficiência com pyrithiobac foi mantida somente nesta modalidade de controle, proporcionando índices ao redor de $90 \%$, se comparando estatisticamente nos dois estádios de crescimento das plantas daninhas. Enquanto nos tratamentos com um única aplicação, nos dois estádios, os índices de controle reduziram-se para a faixa de $70 \%$, tornando-se insuficiente, devido a recomposição matoflorística.

E aos 54 DAA (37 DAA da segunda dose), foram avaliados somente os tratamentos realizados em plantas daninhas em estádio normal de crescimento. E apenas o tratamento com aplicação seqüencial se mantinha eficiente, com índice acima de 92,7\%, comparando-se estatisticamente ao padrão com $98,1 \%$, enquanto na aplicação única o controle foi de $75 \%$.

A planta daninha I. grandifolia, foi eficientemente controlada pelo herbicida pyrithiobac, conforme pode-se observar na Tabela 3. De modo geral, os índices foram superiores ao da espécie anterior. Aos 7 DAA os índices de controle foram semelhantes ao do capimcarrapicho, ou seja, a exceção do tratamento seqüencial no estádio normal de crescimento, ainda deficiente, com índice de $77,6 \%$, nos demais os índices variaram de 81,6 a $85 \%$, embora todos tivessem sido comparados estatisticamente. A partir dos 15 DAA, os índices melhoraram, sendo que aos 44 DAA em qualquer das duas modalidades utilizadas, isto é, aplicação seqüencial ou única, nos estádios inicial e normal das plantas daninhas, os controles situavam acima de $90 \%$. 
Destacando-se a modalidade seqüencial, embora estatisticamente fosse semelhante à aplicação única e ao tratamento padrão. Aos $54 \mathrm{DAA}$, em avaliações no POSn somente, a eficiência foi mantida, independente da modalidade de aplicação. Os melhores resultados de controle para a espécie em questão em relação a anterior, seja em aplicação seqüencial ou única, sobremaneira para esta última, foi atribuído principalmente a sua menor densidade no experimento, ou seja 16 plantas $/ \mathrm{m}^{2}$, contra 112 plantas $/ \mathrm{m}^{2}$ de capim- carrapicho. Pois, com isto, a intensidade da recomposição matoflorística foi baixa, favorecendo desse modo a aplicação única, diferente do capim-carrapicho, em alta densidade, onde a aplicação seqüencial foi melhor.

Quanto a fitotoxicação (Tabela 4), foram observados inicialmente, aos 7 DAA, sinais de injúria à cultura, principalmente com a mesma em estádio inicial de crescimento ( 10 a $15 \mathrm{~cm}$ de altura), no qual os índices foram ao redor de $13 \%$, tanto a dose normal ou com metade dela.

TABELA 4. Médias das porcentagens de fitotoxicação aos 7, 15 e 44 dias após aplicação (DAA) dos tratamentos no experimento com a cultura do algodão. Londrina, PR. 1994/95.

\begin{tabular}{|c|c|c|c|c|c|}
\hline \multirow[t]{2}{*}{ TRATAMENTOS } & \multirow{2}{*}{$\begin{array}{l}\text { MODO DE } \\
\text { APLICAÇÃOO }\end{array}$} & \multirow{2}{*}{$\begin{array}{c}\text { DOSE } \\
\text { (kg ou } 1 \text { p.c./ha) }\end{array}$} & \multicolumn{3}{|c|}{ Fitotoxicação } \\
\hline & & & $7 \mathrm{DAA}^{(1)}$ & $15 \mathrm{DAA}^{(1)}$ & $44 \mathrm{DAA}^{(1)}$ \\
\hline $\begin{array}{l}\text { 1-Testemunha } \\
\text { capinada }\end{array}$ & -- & -- & $0,0 \mathrm{c}$ & $0,0 \mathrm{~d}$ & $0,0 \mathrm{~b}$ \\
\hline $\begin{array}{l}\text { 2-Testemunha s/ } \\
\text { capina }\end{array}$ & -- & -- & $0,0 \mathrm{c}$ & $0,0 \mathrm{~d}$ & $0,0 \mathrm{~b}$ \\
\hline 3-pyrithiobac & PÓS INICIAL ${ }^{(\mathrm{A})}$ & $0,07^{(1)} \ldots 0,07^{(2)}$ & $12,4 \mathrm{a}$ & $10,4 \mathrm{ab}$ & $0,0 \mathrm{~b}$ \\
\hline 4-pyrithiobac & PÓS NORMAL ${ }^{(B)}$ & $0,07^{(1)} \ldots 0,07^{(2)}$ & $1,3 \mathrm{bc}$ & $0,3 \mathrm{~cd}$ & $0,0 \mathrm{~b}$ \\
\hline 5-pyrithiobac & PÓS INICIAL & $0,140^{(1)}$ & $14,8 \mathrm{a}$ & $10,4 \mathrm{ab}$ & $0,0 \mathrm{~b}$ \\
\hline 6-pyrithiobac & PÓS NORMAL & $0,140^{(1)}$ & $7,3 \mathrm{ab}$ & $5,0 \mathrm{bc}$ & $0,0 \mathrm{~b}$ \\
\hline 7-MSMA & PÓS NORMAL & $1,680^{(1)}$ & $17,4 \mathrm{a}$ & $15,0 \mathrm{a}$ & $7,3 \mathrm{a}$ \\
\hline 8-MSMA + diuron & PÓS NORMAL & $2,5+1,4^{(1)}$ & $1,2 \mathrm{bc}$ & $0,3 \mathrm{~cd}$ & $0,0 \mathrm{~b}$ \\
\hline $\mathrm{F}$ & & & $23,3^{* *}$ & $20,9^{* *}$ & $97,0^{* *}$ \\
\hline DMS & & & 9,91 & 9,74 & 2,67 \\
\hline $\mathrm{CV} \%$ & & & 34,61 & 41,19 & 57,43 \\
\hline \multicolumn{3}{|c|}{${ }^{* *}$ significativo ao nível de $5 \%$ de probabilidade } & ${ }^{\text {ns }}$ não sig & icativo & \\
\hline \multicolumn{6}{|c|}{ - Médias seguidas pela mesma letra não diferem entre si pelo Teste de Tukey ao nível de $5 \%$ de probabilidade. } \\
\hline \multirow{2}{*}{\multicolumn{6}{|c|}{$\begin{array}{l}\text { - Os dados originais foram transformados em arc sen raiz quadrada de } \mathrm{x} / 100 \text {. } \\
\text { (1) Primeiro e/ou único tratamento; }\end{array}$}} \\
\hline & & & & & \\
\hline \multicolumn{6}{|c|}{$\begin{array}{l}\text { (1) Primeiro e/ou único tratamento; } \\
\text { (2) Segundo tratamento seqüencial; }\end{array}$} \\
\hline \multicolumn{6}{|c|}{$\begin{array}{l}\text { (2) Segundo tratamento seqüencial; } \\
\text { (A) Pós inicial = Plantas daninhas em }\end{array}$} \\
\hline
\end{tabular}

No entanto a cultura demonstrou mais tolerância quando mais desenvolvida. Pois em estádio de 0,15 a $0,10 \mathrm{~m}$ de altura a injúria foi menor, ou seja, 7,3 e 1,3\% respectivamente nas doses de 0,5 e 0,25 1/ha . Os sinais de injúria começaram a diminuir a partir dos 15 DAA, sendo que aos 44 DAA aparentemente não se observava mais os sinais de fitotoxicação, considerando que os tratamentos seqüenciais já haviam sido aplicados. Sendo que os mesmos não promoveram injúria com o algodoeiro em estádio acima de $30 \mathrm{~cm}$ de altura. O tratamento mais fitotóxico foi com o herbicida MSMA, no qual aos 44 DAA ainda se observava sinais de injúria. 
A altura de plantas também foi determinada. Conforme pode-se verificar na Tabela 5 não houve diferenças significativas entre a altura de plantas na testemunha e nos tratamentos com herbicida, ou seja, o produto pyrithiobac não interferiu no crescimento do algodoeiro.

A produção de fibra foi muito prejudicada pela praga bicudo (Anthonomus grandis), por isso decidiu-se não determinar seu rendimento.

Portanto, quanto a eficiência o herbicida pyrithiobac nas doses testadas, demonstrou excelente desempenho no controle das plantas daninhas capim-carrapicho e corda-de-viola. No entanto, em relação as doses utilizadas, $0,5 \mathrm{e}$ $0,25 \mathrm{l} / \mathrm{ha}$, isto é, dose normal e metade dela, comparativamente demonstraram desempenho semelhante no controle dessas espécies, tanto em estádio inicial como normal de crescimento. Significa então que, para estes estádios, o parcelamento da dose em aplicações seqüenciais é a modalidade de uso mais indicada para o produto, principalmente em razão de certa flexibilidade quanto ao estádio de controle com a dose testada. Isto assinala com a possibilidade de se trabalhar com doses menores do que esta, em função do estádio da planta daninha.

TABELA 5. Médias de altura $(\mathrm{cm})$ de plantas de algodão aos 15 e 30 dias após aplicação (DAA) dos tratamentos no experimento com a cultura do algodão. Londrina, PR. 1994/95.

\begin{tabular}{|c|c|c|c|c|c|c|}
\hline \multirow[t]{2}{*}{ TRATAMENTOS } & \multirow{2}{*}{$\begin{array}{l}\text { MODO DE } \\
\text { APLICAÇÃO }\end{array}$} & \multirow{2}{*}{$\begin{array}{c}\text { DOSE } \\
(\mathrm{kg} \mathrm{ou} \mathrm{l} \mathrm{p.c./ha)}\end{array}$} & \multicolumn{4}{|c|}{ ALTURA } \\
\hline & & & $15 \mathrm{DAA}^{(*)}$ & $30 \mathrm{DAA}^{(*)}$ & $15 \mathrm{DAA}^{(* *)}$ & $30 \mathrm{DAA}^{(* *)}$ \\
\hline $\begin{array}{l}\text { 1-Testemunha } \\
\text { capinada }\end{array}$ & -- & -- & $24,9 \mathrm{a}$ & $37,1 \mathrm{a}$ & $31,0 \mathrm{ab}$ & $51,6 \mathrm{a}$ \\
\hline $\begin{array}{l}\text { 2-Testemunha s/ } \\
\text { capina }\end{array}$ & -- & -- & -- & -- & -- & -- \\
\hline 3-pyrithiobac & PÓS INICIAL (A) & $0,07^{(1)} \ldots 0,07^{(2)}$ & $25,3 \mathrm{a}$ & 35,9 a & -- & -- \\
\hline 4-pyrithiobac & PÓS NORMAL ${ }^{(B)}$ & $0,07^{(1)} \ldots 0,07^{(2)}$ & -- & -- & $34,7 \mathrm{a}$ & 55,8 a \\
\hline 5-pyrithiobac & PÓS INICIAL & $0,140^{(1)}$ & $24,9 \mathrm{a}$ & $35,8 \mathrm{a}$ & -- & -- \\
\hline 6-pyrithiobac & PÓS NORMAL & $0,140^{(1)}$ & -- & -- & $29,5 \mathrm{~b}$ & $46,9 \mathrm{a}$ \\
\hline 7-MSMA & PÓS NORMAL & $1,680^{(1)}$ & -- & -- & $29,6 \mathrm{~b}$ & -- \\
\hline 8-MSMA + diuron & PÓS NORMAL & $2,5+1,4^{(1)}$ & -- & -- & $33,1 \mathrm{ab}$ & -- \\
\hline $\mathrm{F}$ & & & $0,04^{\mathrm{ns}}$ & $0,32^{\mathrm{ns}}$ & $4,77^{* *}$ & $2,62^{\mathrm{ns}}$ \\
\hline DMS & & & 4,22 & 5,14 & 4,69 & 11,96 \\
\hline $\mathrm{CV} \%$ & & & 7,76 & 6,52 & 6,58 & 10,71 \\
\hline \multicolumn{7}{|c|}{ 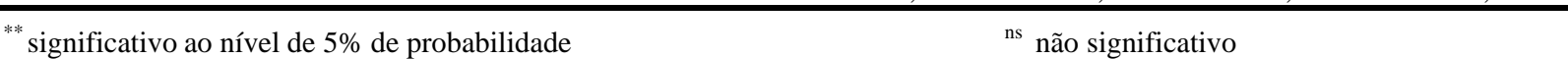 } \\
\hline \multirow{2}{*}{\multicolumn{7}{|c|}{$\begin{array}{l}\text { - Médias seguidas pela mesma letra não diferem entre si pelo Teste de Tukey ao nível de } 5 \% \text { de probabilidade. } \\
\text { (1) Primeiro e/ou único tratamento; }\end{array}$}} \\
\hline & & & & & & \\
\hline \multicolumn{7}{|c|}{ (2) Segundo tratamento seqüencial; } \\
\hline \multicolumn{7}{|c|}{ (A) Pós inicial = Plantas daninhas em estádio de 1 a 3 folhas e o algodoeiro com 10 a $15 \mathrm{~cm}$ de altura; } \\
\hline
\end{tabular}

\section{LITERATURA CITADA}

\section{ALMEIDA, F.S., RODRIGUES, B.N. Guia de herbicidas. $2^{a}$ ed. Londrina-PR.1988. 603p.}

AZEVEDO, D.M.P., VIEIRA, D.J., NOBREGA, L.B., BELTRÃO, N.E.M., FONSECA, J.H. Estudo de doses de diuron e trifluralin no algodoeiro herbáceo. In.: CONGRESSO BRASILEIRO DE HERBICIDAS E 
PLANTAS DANINHAS, $15^{\circ} .1984$.

Resumos... Belo Horizonte: SBHPD, 1984, p. 126. 1984.

BLANCO, H.G. , OLIVEIRA, D.A. Contribuição para determinação do período de competição das plantas daninhas na cultura do algodão (Gossypium hirsutm L.). Biológico, v. 42, n. 9-10, p.201-205, 1976.

CRUZ, L.S.P. Herbicidas na cultura do algodoeiro. Documento Técnico $\mathrm{n}^{\circ} 17$. Área de algodão PF-COT-CATI, Campinas, 1979. $23 \mathrm{p}$.

CRUZ, L.S.P. , BORGO, A. Emprego de misturas de herbicidas nas entre linhas de algodoeiro para controle de plantas daninhas tardia. In.: CONGRESSO BRASILEIRO DE HERBICIDAS E ERVAS DANINHAS, $13^{\circ}, 1980$. Resumos... Ilhéus/Itabuna. SBHED, 1980, p.3.

MARCONDES, D.A.S. , CHEHATA, A.N. Comportamento de trifluralin associado com herbicidas de pré e pós-emergência semi-dirigida, para controle de plantas daninhas na cultura do algodão (Gossypium hirsutum L.). In.: CONGRESSO BRASILEIRO DE HERBICIDAS E PLANTAS DANINHAS, $17^{\circ} .1988$. Resumos... Piracicaba: SBHPD, 1988, p.102-103. 